\title{
MARKETING STRATEGY IMPLEMENTATION: A STUDY OF SMALL AND MEDIUM COMPANIES IN INDONESIA.
}

\author{
Asmai Ishak \\ Fakultas Ekonomi Universitas Islam Indonesia
}

\begin{abstract}
A good marketing strategy does not always necessarily lead to successful marketing performance in an organization. It depends on how marketing people translate the strategy into action. A well formulated, but badly implemented strategy, will be effective (do the right things), but not efficient (do things right). While correct implementation of a badly formulated strategy will be efficient, but not effective. Firms need both effectiveness and efficiency to optimize their performance. This study, based on existing literature, identified a list of activities concerning the marketing strategy implementation, and investigated their nature in the process of the strategy implementation among small and medium companies in Indonesia. A tested structured questionnaire was used as a guidance in interviewing marketing managers -the respondents of the study. A total of 76 completed questionnaires were collected. Factor analysis was used to extract, if any, key dimensions across the data. This analysis resulted into four fundamental factors underlying 16 activities in marketing strategy implementation, namely commitment, consensus, evaluation and control, autonomy, and two factors representing 8 marketing performance that are financial, and strategic performances. Subsequently simple regression was performed to examine the impact of the four factors on the marketing performance. The study findings suggest that evaluation and control has greatest impact either on financial performance or strategic performance, followed by autonomy. Even though commitment and consensus influence the marketing performance, but their influences are not statistically significant.
\end{abstract}

INTRODUCTION

Successful organizations are those that most efficiently correspond with their environments. The responsibility of this environmental contact is typically within the domain of marketing and the development of appropriate marketing strategies. The area of marketing strategy has received considerable attention in the last two decades both in the marketing literature and in the business world. The reasons for this growing interest in this area are varied, but mostly due to the dramatic changes in the overall business environment. Literature on strategic marketing planning points to the view that companies with complete strategic marketing planning systems will be more successful than those without, in environmental and competitive circumstances which are directly comparable (McDonald 1996).

However, given a gap between theory and practice still exist, some obvious contradictions are apparent. As indicated by Greenley \& Bayus (1994) that only $13 \%$ of UK and US companies studied could be described as sophisticated marketing planning decision makers that used marketing strategy as prescribed by literature. Similar findings are also pointed out by Verhage \& Waarts (1988) and McColl et al. (1990). Verhage 
\& Waarts (1988) discovered that only $38 \%$ of Dutch companies described themselves as marketing oriented companies. These companies made annual marketing and long range plan, and had better performance than those did not. Meanwhile, McColl et al. (1990) revealed that while most Australia companies recognized the need for a distinct formal document, not all used them. It would appear that the managers would make decision intuitively, rather than take a time to discuss and plan formally. This could indicate to the low overall awareness and usage of marketing planning.

One of the reasons of this lack of marketing strategy utilization may probably arise from managers' understanding about marketing strategy itself. Many so-called marketing strategies had little or no strategic content. They are no more than budgeting or forecasting (McDonald 1992). Making the marketing strategy work in the real world is another reason. Strategy implementation is not a popular topic with many managers. Too often, sound marketing strategies never come to the expected results. The main cause frequently is some breakdown in implementation. Strategy implementation is an enigma and a source of frustration in many companies (Noble 1999).

\section{BARRIERS IN MARKETING STRATEGY IMPLEMENTATION}

Once the marketing strategy is formulated, the next problem is how to make it for a result of successful marketing performance. In other words, a well formulated marketing strategy does not always attain the intended results. It depends on how good its implementation is. As stated by Vasconcellos e Sa (1990) that a well formulated, but badly implemented strategy, will be effective (do the right things), but not efficient (do things right). While correct implementation of a badly formulated strategy will be efficient, but not effective. Firms need both effectiveness and efficiency to optimize their performance.

Bonoma (1984) for example, revealed that the problems in marketing implementation arose from either in marketing functions, programs, or marketing system. Three causes generally generated problem with marketing functions. First, top management's assumption that the function in question would be executed well by someone else, somewhere else, and thus it was ignored until a crisis intervened. Second cause was structural contradiction. The third one was the failure of top management to pick one of marketing functions for special concentration and competence, instead of taking an adequate satisfaction in doing each marketing function. Meanwhile, the problems in marketing programs occurred because of either inability of employees to execute the program plans, or a lack of direction from top management's execution policies. 
Similarly, Heyer \& Lee (1992) also pointed out some problems in strategy implementation. From their study, it was found that most executives believed that within their companies the strategy was implemented in inconsistent ways with the strategy development. The study also found that common problems in implementing the strategy successfully were organizational barriers. These included uneven or inadequate management skills, a poor comprehension of roles, insufficient coordination across departmental boundaries, unclear lines of accountability, ineffective monitoring, and a general of lack employee commitment. The study also uncovered that the current performance measurement and pay system rewards actually encouraged counterproductive or narrowly focused behavior of the employees.

The main cause of the problems in marketing strategy implementation is the dichotomy the strategy formulation - implementation. As indicated by Cespedes \& Piercy (1996) that many of the difficulties associated with marketing implementation in practice appear to arise, not simply because of practical problems, but because of the view of conventional approach that marketing strategy development and implementation are distinct and sequential activities. From a comprehensive literature review, they conclude that this dichotomy is fraught with following dangers:

- It ignores (or often underestimates) the interaction between the process of marketing strategy formulation and organization's unique implementation capabilities and constraints.

- It reduces the ability of an organization to establish a marketing strategy which draws on its real core competencies, i.e. what it is best at in a particular market or industry.

- Its risks divorcing the plan produced from the changing realities of the inner working of the organization.

- It encourages the establishment of "professional planners and the consequent "uncoupling" of strategy from operating plans.

- It may rely too heavily on the rational-analytical belief that strategies are direct, and are chosen by management, rather than being emergent and growing from experiences and preferences of the organization members.

- It assumes that strategies are problematic and execution is not, which is the reverse of much managerial experience -knowing what to do is relatively easy compared to actually doing it.

- It takes no account of the need for effective strategies to span internal boundaries between functional and organizational interest group.

- It underestimates the significance of the political and negotiating infrastructure within the organization, and its impact on the process of gaining the commitment of organizational members at all levels. 
- It largely ignores the potential for middle management "counterimplementation" efforts.

- It generates increasing opportunity costs for firms, as "time-based" strategies place a premium on a firm's ability to implement plans more quickly than in previous stages of competition.

- Similarly, the formulation - implementation dichotomy can prevent a firm from realizing important first-mover or pioneer advantages as product life cycles become shorter.

- Finally, it has been suggested that the inherent advantage of any given marketing strategy itself is now subject to a shorter "window of opportunity", as global competition, rapid diffusion of technology, and information systems make imitation of successful strategies easier and quicker.

In conclusion, this strategy formulation - implementation dichotomy will not lead to intended result, due to its inability to adjust to fastchanging conditions, especially in highly dynamic environment (Feurer \& Chaharbaghi 1995a).

\section{CURRENT STUDY}

To cope with turbulent business environments, there is a need for a dynamic approach in which strategy formulation and implementation are carried out simultaneously to facilitate objectives' attainment. This represents an ongoing process of analyzing the competitive environments and developing strategic options together with their evaluation. This process should consider the required implementation time-frame and the span of the strategic gap (Feurer \& Chaharbaghi 1995b). In addition, the strategy must be treated as part of individual responsibilities, by distributing the ownership of formulation and implementation throughout the organization. It is believed that by transferring the strategy ownership will improve the information quality used in the strategy formulation, and at the same time, it will reduce potential conflict and timeframe in the strategy implementation (Feurer \& Chaharbaghi 1995a). As stated by Piercy (1992) that the most important and productive thing to focus on strategic marketing planning is not the techniques and the formal methods, it is quite simply commitment and ownership. There are no real rewards for beautifully designed planning systems incorporating latest computerized models. The rewards come from getting the marketing act together and getting people excited and motivated to do the things that matter to customers in the marketplace

Implementing a strategy calls for balancing the course of actions to implement the formulated strategy and maneuvering space for adjustment of the actions set out (Piest \& Ritsema, 1993). This indicates that 
marketing managers call for top-management's commitment in term of authority delegation to implement the strategy.

Finally, managers must always monitor the competitive environments to ascertain the formulated strategy and the course of action still fines tune with the environments. Put in different way, managers must establish control and evaluation to predict whether current actions and strategy would enable achievement of objectives. Continuous monitoring key variables or strategy premises allows the managers to spot any changes, and they can predict their impact on the desired end result (Tadepalli 1992)

Based on the above phenomena, current study considers that marketing managers should present their strategic consensus, strategic commitment, autonomy, and control and evaluation on the formulated strategy to attain the desired performance.

\section{Strategic Consensus}

Floyd \& Wooldridge (1992) define strategic consensus as agreement among top, middle, and operating managers on the fundamental priorities of the organization. The importance of consensus as an internal part of the strategy formulation and implementation processes has long been recognized. There are two conflicting views of the impact of consensus on organizational performance. Most of researchers find that consensus can enhance the performance (Dess, 1987; Rapert, D. Linch \& Suter, 1996). They argue that consensus can reduce the uncertainty and improve the understanding of strategy implementation to attain the selected goals. In contrast, the opponent view advocates that consensus does not relate to the performance, or in some degrees, they may have a negative relationship. As articulated by Janis (1972) that there are some problems inherent in consensus-seeking groups which place an overemphasis on group harmony to the elimination of constructive criticism. However, Rapert, Linch \& Suter. (1996) consider those problems arise because the study focuses on consensus as a mean of reaching a decision rather than an outcome of the decision making itself.

In accordance with Dess (1987 and Rapert, D. Linch \& Suter. (1996), the authors believe that consensus can improve the performance. When the middle and operational managers are assured and understand about what they should do in realizing the formulated strategy, they will present appropriates and supportive behaviour. Otherwise, their behaviour will be unfocused and disorganized.

We hypothesize as follow:

$H_{1}$ : A strategic consensus will have positive effect on organizational performance 


\section{Strategic Commitment}

Strategic commitment is quite similar with the strategic consensus, but it involves a deeper intimacy with the strategy. Strategic commitment refers to a willingness by managers to exert a high level of effort on behalf of the organization, and a sense of identification with the organization's goals, so that managers and organizational goals are closely aligned (Guth \& Macmilan, 1986). Management will gain the managers' commitment if it interest coincides with the self-interest of the managers. Disagreement between the two interests generates a low commitment. To eliminate the gap among the two, there should a dialogue between top management and middle/operational managers to build a mutual understanding - the basis of commitment. Middle managers will commit to a strategy only they are convinced that top management will provide resources and reward appropriate behaviour (Floyd \& Wooldridge, 1992).

In addition, managers with high levels of organizational commitment may still remain uncommitted to a particular course of action. The low commitment may result a passive compliance, or even worse, an "upward" intervention. Uncommitted managers may give implementation a low priority, create implementation obstacles, or even sabotage the strategy. The lack of commitment may also lead to information distortion and promotion alternative strategies (Rapert, D. Linch \& Suter,. 1996). This makes managers' commitment have crucial role for effective strategy implementation. We hypothesize as follow:

$\mathrm{H}_{2}$ : A strategic commitment will have positive influence on organizational performance.

\section{Autonomy}

A dynamic approach to the strategy implementation requires an internal environment that provides a high degree of stability while at the same time offering a high degree of flexibility to respond any changes quickly (Feurer \& Chaharbaghi, 1995a). Strategies, as a guidance or direction for middle/operational managers, usually tend to be worded in more or less abstract. If the strategy is too abstract, it will make some difficulties for the managers or even lead to a wrong direction due to incorrect interpretation. On the contrary if the strategy is too detail, it will eliminate managers' creativity, and make the managers inflexible to implement it.

Therefore, especially in the case of a turbulent and dynamic environment, management must be careful when trying to make the strategies explicit to remain a large enough degree of freedom for adapting environmental changes. As stated by Piest \& Ritsema, (1993) that in implementing strategy managers have to find the right balance between direction and 
creativity. In other words, the managers call for top-management's commitment in term of clear direction and authority delegation to implement the strategy. Managers need certain autonomy for interpreting the formulated strategy correctly, and making any revision to adapt environmental changes. Especially in fast-changing conditions, managers always have to make some revision to adapt any changes before being late. Thus, without enough autonomy, the strategy could not be adjusted in the right time.

We hypothesize as follows:

$\mathbf{H}_{3}$ : Autonomy will have positive affect on organizational performance.

\section{Control and Evaluation}

Control and evaluation has various aspects. Piest \& Ritsema (1993) classifies control into internal and external controls. Internal control relates to the evaluation of activities that take place within organization. The internal control is manager's mean to see the extent the formulated strategies have been implemented. It also enables the managers to see whether the organization has engaged in other activities which are not part of the formulated strategy to implement. Through internal control functional managers can also evaluate whether their strategies in alignment with other functional and organizational strategies. This strategy alignment will smooth the strategy implementation in attaining intended performance (Feurer \& Chaharbaghi, 1995b).

On the hand, external control relates the evaluation of external environment. Every strategy is based on a number of key assumptions as starting points of its formulation. It is assumed that certain things will be happened in certain way. Unfortunately, business environment is so uncertain. External control is concerned with the validation of these assumptions. Due to the unpredictability of the environment, managers should not only predict the environmental changes, but also monitor the key assumptions of the environment continuously. This enables them to control any deviations before they take place (Tadepalli, 1992). Continuous monitoring also allows the managers to respond the environmental changes quickly and evaluate their impact the performance desired.

We hypothesize as follow:

$\mathbf{H}_{4}$ : Control and evaluation has a positive influence on organizational performance.

\section{Organization Performance}

There is no uniform definition of the firm performance in the literature. The most frequently used performance parameters seem to be economic in nature, such as sales, sales growth, profits etc. A firm is usually 
established to attain some objectives that can be economic: profits, sales, cost; and/or strategic: market expansion, customer satisfaction, product quality improvement, and the like. This study will combine both economic and strategic dimensions to measure the firm performance. Therefore the performance is defined as the extent to which a firm's objectives, both economic and strategic, are achieved through planning and execution of marketing strategy (Cavusgil \& Zou, 1994).

\section{RESEARCH METHODOLOGY}

\section{Sample Selection}

Most of previous studies in marketing strategy implementation were held in developed countries. Almost none of them used any companies in developing countries for their research objects. This study employed small and medium company in Indonesia, to test applicability of the previous findings in developing countries. A stratified sampling method was used to ensure that the organizations selected represented their industries in term of size and type. A list of 93 companies selected from Central Bureau of Statistics - Indonesia. The only requirement of the respondent was that s/he had to be Marketing Manager or person who responsible for the implementation of marketing strategy in the company.

The survey instruments were evaluates by Indonesian businessmen and academicians. Some wording corrections were done after a pretest questionnaires through some marketing executives. Both pre-test questionnaires and data collection were done through structured personal interview. The personal interviews were used in this study for the following two reasons:

- To ensure that the respondents clearly understand and not misinterpret every question being asked to minimize the respondent bias (Sekaran, 2000)

- To ensure that we get certain number of complete answered questionnaires. It could not be done through the mail questionnaires.

From the list of 93 companies, only 75 managers agreed to be interviewed and answered the questionnaires. The others were unwilling to do so due to too busy with their paper work or did not implement marketing strategy specifically. $53.3 \%$ of the respondents could be classified as small companies with annual sales not more than 25 billions rupiah, while the other $46.7 \%$ were medium companies with annual sales between 26 billion to 250 billion rupiah. Unintentionally, our respondents had same proportion as their companies were classified based on industry. $53.3 \%$ of them were operated in consumer good industry, whereas the other $46.7 \%$ were run in industrial good industry. 


\section{Measurement}

Strategic consensus and commitment are measured using five point scales, ranging form "strongly disagree" to "strongly agree", developed by Rapert, D. Linch \& Suter. (1996) and Wooldrigde \& Floyd (1990) with some modification to facilitate the interview. Marketing managers were asked to evaluate the extent their believes in the appropriateness of and commitment toward the formulated marketing strategy.

Autonomy refers to the extent of authority delegation to the marketing manager to implement the marketing strategy. Autonomy is measured through five point scale ranging form "strongly disagree" to "strongly agree". Drawing from the literature, the items focus on the extent of authority to revise and change the formulated strategy to adapt the environmental changes, and to improve the skill of their staff. Marketing manager were asked to indicate their autonomy in relation to these items.

Control and evaluation reflects the continuation level of marketing manager in monitoring their business environment internally and externally. Similar to the other measurement in this study, control and evaluation is measured using five point scale, form "strongly disagree" to "strongly agree". From reviewing the literature, the items concentrate on the extent of regularity to monitor business environment, to control and evaluate the alignment of the marketing strategies and program with the external environment, and to assure the alignment the strategies and program with the others to minimize potential conflict.

Performance is measured in term of (a) economic dimension, such as return on investment, profit margin, and market share; and (b) strategic dimension, like increase in the awareness of product, response to competitive pressures, increase in the profitability of the company, improvements in the market share, expand strategically into new market. Marketing managers were asked to indicate, on a five point bipolar scales ranging from "significantly below average" to "significantly above average", about the attainment of economic goals relative to corporate standards. While on strategic goals, marketing managers were asked to indicate the rate their successfulness on a five point bipolar scales ranging from "unsuccessful" to "successful".

\section{DATA ANALYSIS}

Prior to the analyses, a paired-means test between small and medium companies was carried out with respect to the economic and strategic performances. There was no significant difference detected among the small and medium companies on these two performance scales. All variables investigated were also subjected to reliability assessment. Table 1 
includes the Cronbach alpha for the six constructs. Their scores are ranging from 0.65 to 0.83 . Taking Nunnaly's threshold of acceptable reliability coefficients equals to or greater than 0.50 , the constructs used in this study were acceptably robust.

Factor analysis was employed to reduce the number of variables. The analysis compresses 24 variables into 6 construct variables, i.e. strategic consensus, strategic commitment, evaluation \& control, autonomy, economic performance, and strategic performance. Table 1 summarizes the single-factor solutions provided by each factor analysis. The eigenvalue of the factors are ranging from 1.78 to 2.55 which account for $51.8 \%-75.4 \%$ of variability. Meanwhile, the factor loadings range from 0.242 to 0.888 . For example, the single factor for strategic consensus reports an eigenvalue of 2.13 accounting for $71 \%$ of the variability. Its factor loadings vary from 0.807 to 0.877 . Taking threshold of acceptable significant factor loading equals to or greater than 0.65 for sample size of 75 (Hair et.al, 1998), four variables should be excluded from three constructs for further analysis. Two variables excluded from the strategic commitment construct, one variable from each of the autonomy and strategic performance constructs.

Correlation analysis indicated that all of the variables of marketing strategy implementation (strategic consensus and commitment, evaluation \& control, and autonomy) correlated significantly to both economic and strategic performances (see Table $2 \mathrm{a}$ and Table $2 \mathrm{~b}$ ). The highest correlation coefficient to the performance was the evaluation \& control, while the lowest one was the strategic consensus. 
Table 1. Factor Loadings and Reliabilities

\begin{tabular}{|c|c|}
\hline Variable Names & Factor Loadings \\
\hline $\begin{array}{l}\text { Consensus }{ }^{a} \text { : } \\
\text { People in this department feel that this company is pursuing the best marketing strat- } \\
\text { egy for achieving our desired goals }\end{array}$ & .843 \\
\hline $\begin{array}{l}\text { People in this department are in full agreement with the overall strategy of this com- } \\
\text { pany }\end{array}$ & .807 \\
\hline $\begin{array}{l}\text { People in this department feel that, through this strategy, this company is applying its } \\
\text { resources in the most efficient and constructive manner. }\end{array}$ & .877 \\
\hline $\begin{array}{l}\text { Commitment } \mathrm{b} \text { : } \\
\text { People in this department believe that the marketing strategic priorities are similar to } \\
\text { the organization }\end{array}$ & .489 \\
\hline $\begin{array}{l}\text { People in this department would accept almost any type of job assignment in order to } \\
\text { keep working toward the strategic priority }\end{array}$ & .674 \\
\hline $\begin{array}{l}\text { People in this department strongly believe that this strategic priority will go a long way } \\
\text { in aiding this company's performance }\end{array}$ & .724 \\
\hline People in this department are excited to tell others about this strategy & .242 \\
\hline $\begin{array}{l}\text { The marketing strategy inspires the best in the way of job performance in this depart- } \\
\text { ment }\end{array}$ & .810 \\
\hline $\begin{array}{l}\text { People in this department are glad that this company chose this marketing strategy } \\
\text { over others it has considered }\end{array}$ & .735 \\
\hline $\begin{array}{l}\text { Evaluation \& Control } \mathrm{c} \text { : } \\
\text { We always monitor our business environment }\end{array}$ & .888 \\
\hline $\begin{array}{l}\text { We carry out routine evaluation and control of our marketing strategies and programs } \\
\text { to ascertain their alignment with the business environment }\end{array}$ & .861 \\
\hline We establish appropriate communication to minimize intra and inter-functional conflict & .856 \\
\hline $\begin{array}{l}\text { Autonomy }{ }^{\mathrm{d}} \text { : } \\
\text { We adjust our marketing strategies and programs to cope with environmental changes }\end{array}$ & .845 \\
\hline We have the autonomy to adjust our marketing strategies and programs & .770 \\
\hline Our marketing personnel have appropriate and adequate marketing skills & .577 \\
\hline We authorize to upgrade the skills of our marketing personnel regularly & .750 \\
\hline $\begin{array}{l}\text { Economic Performance }{ }^{\mathrm{e}} \text { : } \\
\text { Return on investment }\end{array}$ & .764 \\
\hline Profit margin & .765 \\
\hline Market share & .781 \\
\hline $\begin{array}{l}\text { Strategic Performance }{ }^{f} \text { : } \\
\text { Increase the awareness of the product/company }\end{array}$ & .605 \\
\hline Respond to competitive pressures & .786 \\
\hline Improve market share position of the company & .711 \\
\hline Increase the profitability of the company & .733 \\
\hline Expand strategically into new markets & .726 \\
\hline
\end{tabular}

${ }^{\mathrm{a}} \alpha=$.7953; eigenvalue $=2.13$ and $\%$ of variance 71.0

${ }^{b} \alpha=.7406$; eigenvalue $=2.47$ and $\%$ of variance 41.2 .

${ }^{c} \alpha=.8338$; eigenvalue $=2.26$ and $\%$ of variance 75.4

${ }^{\mathrm{d}} \alpha=.7463$; eigenvalue $=2.20$ and $\%$ of variance 55.1

${ }^{\mathrm{e}} \alpha=.6538$; eigenvalue $=1.78$ and $\%$ of variance 59.3

${ }^{\mathrm{f}} \alpha=.7406$; eigenvalue $=2.55$ and $\%$ of variance 51.1 
Table 2a. Correlation between Economic Performance and Marketing Strategy Implementation Variables

\begin{tabular}{|l|c|c|c|c|}
\hline \multicolumn{1}{|c|}{ Variable Name } & $\begin{array}{c}\text { Economic Per- } \\
\text { formance }\end{array}$ & Autonomy & $\begin{array}{c}\text { Evaluation \& } \\
\text { Control }\end{array}$ & Commitment \\
\hline Autonomy & $.618^{* *}$ & - & - & - \\
\hline Evaluation \& Control & $.723^{* *}$ & $.698^{* *}$ & - & - \\
\hline Commitment & $.673^{* *}$ & $.610^{* *}$ & $.582^{* *}$ & - \\
\hline Consensus & $.469^{* *}$ & $.498^{* *}$ & $.573^{* *}$ & $.330^{* *}$ \\
\hline
\end{tabular}

** Correlation is significant at the 0.01 level (2-tailed).

Table 2b. Correlation between Strategic Performance and Marketing Strategy Implementation Variables

\begin{tabular}{|l|c|c|c|c|}
\hline \multicolumn{1}{|c|}{ Variable Name } & $\begin{array}{c}\text { Strategic } \\
\text { Performance }\end{array}$ & Autonomy & $\begin{array}{c}\text { Evaluation \& } \\
\text { Control }\end{array}$ & Commitment \\
\hline Autonomy & $.513^{* *}$ & - & - & - \\
\hline Evaluation \& Control & $.686^{* *}$ & $.698^{* *}$ & - & - \\
\hline Commitment & $.567^{* *}$ & $.610^{* *}$ & $.582^{* *}$ & - \\
\hline Consensus & $.461^{* *}$ & $.498^{* *}$ & $.573^{* *}$ & $.330^{* *}$ \\
\hline
\end{tabular}

${ }^{* \star}$ Correlation is significant at the 0.01 level (2-tailed).

The above correlations are strengthened by individual regression analysis. All of the strategy implementation variables influence the both performances, positively and significantly. Evaluation \& control has the highest influence on the performance, followed by strategic commitment, whereas strategic consensus has the lowest impact (see Table 3). However, when those strategy implementation variables taken together as the independent variables, only two variables significantly influence the performance. Stepwise regression analysis indicates that evaluation \& control and strategic commitment affect both economic and strategic performances positively (see Table 4).

Table 3. Individual Regression Analysis between Performance and Marketing Strategy Implementation Variables

\begin{tabular}{|l|l|c|c|c|c|c|c|}
\hline \multirow{2}{*}{ Dependent Variables } & \multirow{2}{*}{ Independent Variables } & \multirow{2}{*}{$\mathbf{R}$} & \multirow{2}{*}{ Beta } & \multicolumn{2}{|c|}{ F test } & \multicolumn{2}{c|}{$\mathrm{t}$ test } \\
\cline { 5 - 8 } & & Square & & Value & Sign. & Value & Sign. \\
\hline Economic Performance & Evaluation \& Control & .522 & .723 & 79.869 & .000 & 8.937 & .000 \\
\hline Economic Performance & Commitment & .453 & .673 & 60.471 & .000 & 7.776 & .000 \\
\hline Economic Performance & Autonomy & .381 & .618 & 44.999 & .000 & 6.708 & .000 \\
\hline Economic Performance & Consensus & .220 & .469 & 20.558 & .000 & 4.534 & .000 \\
\hline & & & & & & & \\
\hline Strategic Performance & Evaluation \& Control & .471 & .686 & 64.967 & .000 & 8.060 & .000 \\
\hline Strategic Performance & Commitment & .322 & .567 & 34.591 & .000 & 5.881 & .000 \\
\hline Strategic Performance & Autonomy & .263 & .513 & 26.075 & .000 & 5.106 & .000 \\
\hline Strategic Performance & Consensus & .213 & .461 & 19.713 & .000 & 4.440 & .000 \\
\hline
\end{tabular}


Table 4. Stepwise Regression Analysis between Performance and Marketing Strategy Implementation Variables

\begin{tabular}{|l|l|c|c|c|c|c|c|}
\hline \multirow{2}{*}{ Dependent Variables } & \multirow{2}{*}{ Independent Variables } & $\mathbf{R}$ & \multirow{2}{*}{ Beta } & \multicolumn{2}{|c|}{$\mathrm{F}$ test } & \multicolumn{2}{|c|}{$\mathrm{t}$ test } \\
\cline { 5 - 8 } & & Square & & Value & Sign. & Value & Sign. \\
\hline Economic Performance & Evaluation \& Control & \multirow{2}{*}{.619} & .501 & 58.443 & .000 & 5.595 & .000 \\
\cline { 6 - 8 } & & & .382 & & & 4.266 & .000 \\
\hline & & & & & & & \\
\hline Strategic Performance & Evaluation \& Control & \multirow{2}{*}{.500} & .539 & 37.980 & .000 & 5.328 & .000 \\
\cline { 1 - 3 } & Commitment & & .253 & & & 2.507 & .014 \\
\hline
\end{tabular}

From the above analysis, only hypothesis $2\left(\mathrm{H}_{2}\right)$ and $4\left(\mathrm{H}_{4}\right)$ are supported, that are strategic commitment and evaluation \& control have positive effect on the organizational performance. Although the influence of strategic consensus and autonomy on performance do not supported, but it does not mean that they do not have any influence at all. They do have an influence on the performance, but an indirect one. They influence the organizational through strategic commitment and evaluation \& control. Their high correlations with evaluation \& control and strategic commitment indicate these effects.

\section{CONCLUSION}

It is too often that top management formulate the marketing strategy, and leave the marketing manager to implement it. Consequently, the implementation of the strategy does not end to the intended results. Many researchers have recognized this separation of the formulation and implementation of the strategy as the main reason for the failure of the strategy implementation. This separation eliminates the involvement of the operating manager in the strategy formulation processes to gain better understanding of the formulated strategy. Shared understanding is a prerequisite for managers' commitment in implementing the strategy (Wooldridge \& Floyd, 1990; Piest \& Ritsema, 1993; Rapert, Linch \& Suter, 1996). It also facilitates the managers to evaluate and control the business environment to make the strategy always fine tune with its environment (Feurer, Chaharbaghi, \& Wargin, 1995; Tadepalli, 1992). The present study arrives at a similar conclusion in that higher performance levels are associated with marketing managers' evaluation and control and commitment to the strategy. The findings of the present study suggesting that top management should actively engage support from operational managers to achieve better performance.

In addition, the present study represents an initial exploration of some aspects in the strategy implementation in developing country. Much remains to be learned about both the antecedents and consequences of the 
evaluation \& control and the strategic commitment. The future research should also considered the operational managers' involvement in the strategy decision processes, behavioral problems during formulation process, reward system, and managers' analytical skill which can enhance their commitment and control the formulated strategy. It should also consider additional measure of other performance-related outcome, such as job satisfaction.

Finally, as the contribution of marketing functional area to the organizational success becomes apparent, marketing managers must have commitment to and control \& evaluation of the organization strategy.

\section{REFERENCES}

Bonoma, T. V. (1984), "Making Your Marketing Strategy Work", Harvard Business Review, 62, March/April, pp. 69 - 76.

Cavusgil, S. T. \& Zou, S. (1994), "Marketing strategy-performance relationship: An investigation of the empirical link in export market ventures", Journal of Marketing, 58, Jan., pp. 1-21.

Cespedes, F. V. \& Piercy, N. F. (1996), "Implementing Marketing Strategy", Journal of Marketing Management, 12, pp. 135-160.

Dess, G. G. (1987), "Consensus on Strategy Formulation and Organzational Performance: Competitors in A Fragmanted Industry", Strategic Management Journal, 8, pp. 259 - 277.

Feurer, R. \& Chaharbaghi, K. (1995a), "Strategy Development: Past, Present and Future", Management Decision, 33, 6, pp. 11-21.

Feurer, R. \& Chaharbaghi, K. (1995b), "Dynamic Strategy Formulation and Alligment", Journal of General Management, 20, 3, pp. 76-90.

Floyd, S. W. \& Wooldridge, B. (1992), "Managing Strategic Consensus: The Foundation of Effective Implementation", Academy of Management Executive, 6, 4, pp. 27-39.

Greenley, G. E. \& Bayus, B. L. (1994), "Marketing Planning Processes in UK and US Companies.", Journal of Strategic Marketing, 2, pp. 140-154.

Guth, W. D. \& Macmilan, I. C. (1986), "Strategy Implementation Versus Middle Management Self-Interest", Strategic mnagement Journal, 7, pp. $313-327$.

Hair, Jr., J. F., Anderson, R. E., Tatham, R. L., and Black, W. C. (1998), Multivariate Data Analysis, Prentice Hall, Inc., USA, Fifth Edition. 
Heyer, S. J. \& Lee, R. V. (1992), "Rewiring the Corporation", Business Horizons, 35, 3, pp. 13-22.

Janis, I. L. (1972), Victims of Groupthink: Psychological Studies of Foriegn Policy Decisions and Fiascoes, MA: Houghton-Mifflin: Boston, cited in Rapert et.al. (1996).

McColl, K., R. Janet, O. H. M. You \& Keil, G. C. (1990), "Marketing Planning Practices in Australia: A Comparison across Company Types", Marketing Intelligence \& Planning, 8, 4, pp. 21-29.

McDonald, M. (1996), "Strategic Marketing Planning: Theory, Practice and Research Agenda", Journal of Marketing Management, 12, pp. 5-27.

McDonald, M. H. B. (1992), "Ten Barriers to Marketing Planning", Journal of Business and Industrial Marketing, 7, 1 (Winter), pp. 5 - 18.

Noble, C. H. (1999), "Building the Strategy Implementation Network", Business Horizons, November-December, pp. 19 - 28.

Piercy, N. (1992), Market-Led Strategic Change, Butterworth-Heinemann: Oxford.

Piest, B., \& Ritsema, H. R. (1993), "Corporate Strategy: Implementation and Control", European Management Journal, 11, 1, pp. 122-131.

Rapert, M. I., D. Linch \& Suter., T. (1996), "Enhancing Functional and Organizational performance via Strategic Consensus and Commitment.", Journal of Strategic Marketing, 4, pp. 193-205.

Sekaran, U. (2000), Research Methods for Business: A Skill - Building Approach, Third edn, John Willey \& Sons, Inc.: USA.

Tadepalli, R. (1992), ": Marketing Control: Reconceptualization and Implementation Using the Feedforward Method", : European Journal of Marketing, 26, 1, pp. 24-40.

Vasconcellos e Sa, J. D. (1990), "How to Implement a Strategy", Business, 40, 2, pp. 23 - 32.

Verhage, B. \& Waarts, E. (1988), "Marketing Planning for Improved Performance: A Comparative Analysis", International Marketing Review, 5, Summer, pp. 20 - 30.

Wooldrigde, B. \& Floyd, S. W. (1990), "The Strategy Process, Middle Management Involvement, and Organizational Performance", Strategic Management Journal, 11, pp. 231-241. 